
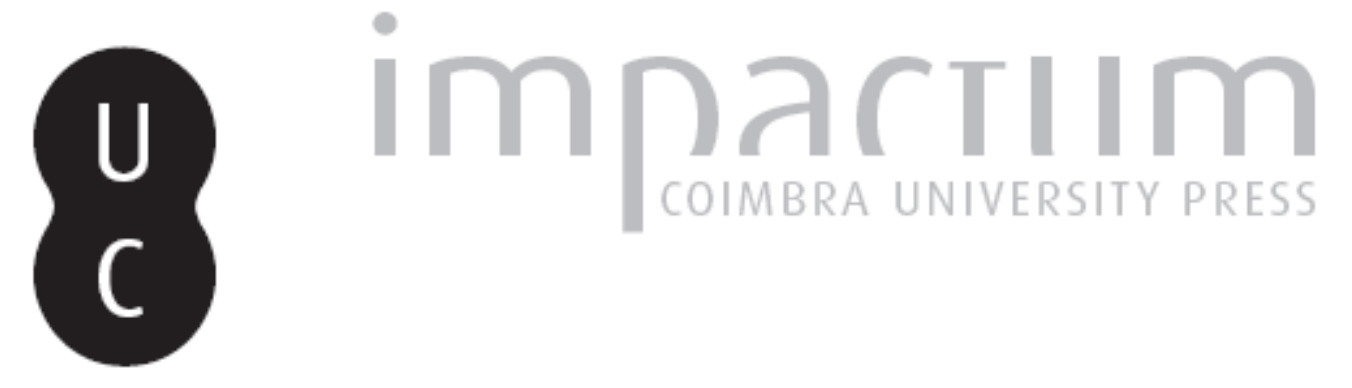

\title{
Guilherme de Poitiers e o relato da batalha de Hastings, 950 anos depois
}

Autor(es): $\quad$ Monteiro, João Gouveia

Publicado por: Imprensa da Universidade de Coimbra

URL persistente:

URI:http://hdl.handle.net/10316.2/40951

DOI:

DOI:https://doi.org/10.14195/1645-2259_16_1

Accessed : $\quad$ 26-Apr-2023 15:47:51

A navegação consulta e descarregamento dos títulos inseridos nas Bibliotecas Digitais UC Digitalis, UC Pombalina e UC Impactum, pressupõem a aceitação plena e sem reservas dos Termos e Condições de Uso destas Bibliotecas Digitais, disponíveis em https://digitalis.uc.pt/pt-pt/termos.

Conforme exposto nos referidos Termos e Condições de Uso, o descarregamento de títulos de acesso restrito requer uma licença válida de autorização devendo o utilizador aceder ao(s) documento(s) a partir de um endereço de IP da instituição detentora da supramencionada licença.

Ao utilizador é apenas permitido o descarregamento para uso pessoal, pelo que o emprego do(s) título(s) descarregado(s) para outro fim, designadamente comercial, carece de autorização do respetivo autor ou editor da obra.

Na medida em que todas as obras da UC Digitalis se encontram protegidas pelo Código do Direito de Autor e Direitos Conexos e demais legislação aplicável, toda a cópia, parcial ou total, deste documento, nos casos em que é legalmente admitida, deverá conter ou fazer-se acompanhar por este aviso.

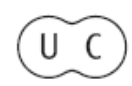




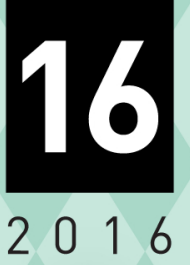

\section{Revista \\ de História \\ da Sociedade \\ e da \\ Cultura}




\title{
Guilherme de Poitiers e o relato da batalha de Has- tings, 950 anos depois
}

\section{William of Poitiers and the battle of Hastings story 950 years later}

\author{
JoÃo Gouveia Monteiro \\ Universidade de Coimbra - CHSC \\ joao.g.monteiro@sapo.pt
}

Texto recebido em / Text submitted on: 27.02.2016

Texto aprovado em / Text approved on: 18.06.2016

Resumo: Este artigo visa evocar, no ano em que se comemora o $950^{\circ}$ aniversário da sua ocorrência, aquele que é considerado o combate mais decisivo da história medieval europeia: a batalha de Hastings, travada a 14 de outubro de 1066, no sul de Inglaterra, entre o rei Haroldo II Godwinson e o duque Guilherme de Normandia. E fá-lo de uma forma muito especial, oferecendo ao público de língua portuguesa a tradução dos parágrafos alusivos a este combate redigidos entre 1071 e 1077 pelo clérigo Guilherme de Poitiers, habitualmente citado como a fonte escrita mais importante do evento. $\mathrm{O}$ artigo compõe-se de uma introdução (em que se apresenta o autor da narrativa e se recordam os momentos principais da sua vibrante descrição do combate) e de um apêndice, em que se transcreve a fonte latina e se apresenta (julgamos que pela primeira vez, pelo menos em versão bilingue) a respetiva tradução portuguesa.

Palavras-chave: batalha de Hastings, conquista normanda de Inglaterra, Guilherme II da Normandia, Harold II Godwinson, guerra medieval.

Abstract: This paper aims to evoke, in the year of the commemoration of the $950^{\text {th }}$ anniversary of its occurrence, the one that is considered the most decisive battle of European medieval history: the Battle of Hastings, fought on October 14, 1066, in southern England, between King Harold II Godwinson and the Duke William of Normandy. And this is done in a very special way, providing to the Portuguese-speaking public the translation of the paragraphs alluding to this combat which were produced between 1071 and 1077 by the clergyman William of Poitiers usually quoted as the most important written source of the event. The article consists of an introduction (in which the narrative's author is presented and the main moments of his vibrant combat's description are recalled) and an appendix, where the Latin text is transcribed and the corresponding Portuguese translation presented (we believe that for the first time, at least in a bilingual version).

Keywords: battle of Hastings, Norman conquest of England, William II of Normandy, Harold II Godwinson, Medieval war. 


\section{Apresentação}

A batalha de Hastings, travada no sul de Inglaterra (a uma dúzia de quilómetros da costa) no dia 14 de outubro de 1066, opôs a melhor cavalaria que a Europa ocidental conhecera desde os exércitos carolíngios (a cavalaria normanda) a uma das melhores infantarias coevas (a infantaria anglo-saxónica). Em resultado deste combate, Guilherme, o segundo duque da Normandia e o líder do exército invasor, tornar-se-ia rei de Inglaterra (foi coroado em Westminster no Natal de 1066), sucedendo assim ao seu rival e antigo aliado Haroldo II Godwinson, que encontrou a morte no campo de batalha de Hastings.

O combate parece ter sido excecionalmente demorado (talvez umas nove horas), o que mostra como a luta foi tremendamente renhida, com ambas as hostes a fazerem jus aos seus pergaminhos marciais. No fundo, a parada era altíssima, pois estava em causa a possibilidade de uma potência estrangeira (a Normandia) conquistar de uma só penada um dos mais ricos e apetecíveis reinos europeus: a Inglaterra. A vitória de Guilherme fez com que este país 'mudasse de mãos' e com que se tivesse, a partir de então, constituído uma espécie de reino transcanal da Mancha, com os monarcas de Inglaterra a dominarem, simultaneamente, a Normandia e outros territórios da atual França. A médio prazo, isso possibilitaria o florescimento do célebre Império Angevino, de que foi principal titular o rei Henrique II Plantageneta (1154-1189), filho de uma neta de Guilherme "O Conquistador" e marido daquela que foi, talvez, a mulher mais famosa do século XII europeu - Leonor da Aquitânia, de quem teve vários filhos, entre os quais dois que a História e a Sétima Arte celebrizaram: Ricardo "Coração de Leão" e João "Sem Terra". Como é bem sabido, o citado entrelaçamento franco-britânico estaria na origem de muitas disputas nos séculos seguintes e só conheceria o seu termo com a vitória da coroa da flor-de-lis na Guerra dos Cem Anos, em 1453.

Estamos, assim, perante uma batalha decisiva, ou seja, perante uma batalha que produziu um efeito que muito dificilmente teria ocorrido se este combate não se tivesse realizado, o que não é vulgar na história do Ocidente, desde a época recuada das falanges hoplitas. Pela sua repercussão política, pela qualidade e elevado número de efetivos empregues nas hostes em presença (cerca de 10000 Ingleses contra 7000 ou 8000 Normandos) e pela duração excecional do combate, não admira que os historiadores militares de hoje concordem em considerar Hastings como o acontecimento militar mais relevante de toda a história medieval europeia! 
Mas a dimensão inusitada do evento foi desde logo sentida pelos observadores contemporâneos. De tal modo que dispomos ainda hoje de uma quantidade invulgar de testemunhos sobre esta batalha, alguns deles veiculando a perspetiva normanda do acontecimento, outros exprimindo o ponto de vista dos vencidos - os Ingleses.

Entre estas últimas fontes, devemos destacar a Crónica Anglo-Saxónica, uma designação genérica que engloba uma série de anais que foram escritos em inglês antigo, em diferentes centros monásticos anglo-saxónicos. Trata-se de relatos aparentados mas, ainda assim, distintos, que devem ter constituído versões diferentes de um trabalho começado ainda no tempo do rei Alfredo "o Grande" (871-899), sob a forma de registos ano a ano e não de uma narrativa estruturada e contínua, em forma de uma verdadeira "crónica”. Com isto, a obra, tornada 'património monástico comum', foi conhecendo acrescentos posteriores nesta ou naquela abadia, circunstância que deu origem a versões ligeiramente diferentes. No fundo, o que acontecia é que uma casa religiosa beneditina tomava de empréstimo a versão de uma outra casa e depois tratava de interpolar os acontecimentos e comentários que entendia, de acordo com as suas necessidades e conveniências. Existem hoje cinco versões principais da Crónica Anglo-Saxónica, das quais três abrangem o período compreendido entre 1042 e 1079, incluindo portanto a batalha de Hastings; duas dessas versões devem ter sido compostas na região de York, e a outra no mosteiro de Peterborough, a sudeste de Lincoln ${ }^{1}$.

Na primeira metade do século XII, em Worcester (não longe de Oxford), um monge de nome João deve ter-se servido de uma versão entretanto perdida da Crónica Anglo-Saxónica, assim como de diversos outros materiais (incluindo obras de Beda "O Venerável”, de Asser e de Guilherme de Malmesbury, entre outras) para compor o seu Chronicon ex Chronicis, uma compilação de narrativas que começa com a Criação do mundo e que termina em 1140. Este trabalho de João de Worcester, eventualmente iniciado por um seu antecessor de nome Florêncio, oferece-nos a particularidade de apresentar um ponto de vista dos acontecimentos de 1066 depurado pela adaptação anglo-saxónica que se seguiu à conquista normanda (Morillo 1996: 29-32).

De entre as fontes normandas, uma há que merece uma atenção e um carinho especiais, pois depressa se tornou um caso singular e um dos mais belos documentos iconográficos medievais: refiro-me ao notável bordado

\footnotetext{
Para um conhecimento selecionado e análise crítica das principais fontes (normandas e anglo-saxónicas) alusivas à batalha de Hastings, é obrigatório ver-se Morillo 1996.
} 
histórico conhecido como a "Tapeçaria de Bayeux", produzido pouco tempo depois da batalha e destinado, ao que tudo indica, a valorizar a cerimónia de dedicação da catedral de Bayeux (uma praça da Normandia, não longe de Caen), que teve lugar em 1077. Trata-se de uma obra artesanal de grande requinte, provavelmente fabricada em Inglaterra (talvez em Canterbury, onde existia uma grande escola de bordado decorativo em que predominavam um design e uma técnica manufatureira semelhantes) por ordem do bispo Odão de Bayeux, meio-irmão do duque Guilherme e testemunha ocular do combate ${ }^{2}$. A Tapeçaria de Bayeux é formada por oito peças que foram habilidosamente cosidas umas às outras de forma a comporem um único e extenso painel com mais de 70 metros de comprimento e apenas meio metro de altura. A tela base de suporte é feita de linho branco e sobre ela foi depois inscrito um bordado colorido à base de tons de vermelho, verde, azul e castanho-amarelado. A narrativa principia em 1064, com os antecedentes do conflito entre Guilherme e Haroldo II, e é documentada por centenas de figuras humanas e animais, para além da representação de muitos equipamentos militares, de navios e de alguns edifícios. As diversas cenas são, curiosamente, separadas por árvores retorcidas e, pormenor nada despiciendo, o bordado inclui pari passu uma legenda em latim que enriquece extraordinariamente este documento e que leva a que ele seja considerado, por muitos, como a banda desenhada mais antiga do mundo... É um grande privilégio (e, tendo em conta aquilo que se sabe acerca do seu acidentado percurso, um autêntico milagre) que a Tapeçaria de Bayeux tenha chegado quase completa aos nossos dias e possa ser hoje comodamente apreciada no museu que the foi dedicado em Bayeux (o Centre Guillaume-le-Conquérant).

Entre as fontes escritas de orientação normanda, devemos destacar dois casos. Por um lado, a Gesta Normannorum ducum ("Gesta dos Duques dos Normandos"), composta cerca de 1070 por um clérigo normando com fortes ligações a Inglaterra, chamado Guilherme de Jumièges. Embora o seu relato sobre a batalha de Hastings se dilua um pouco no conjunto da narrativa (uma história de todos os duques normandos, e não apenas de "O Conquistador”), a descrição de Guilherme de Jumièges parece ter conhecido grande sucesso na época e terá tido uma difusão bastante alargada, tendo mesmo sido copiada e interpolada por vários cronistas posteriores, entre os quais Orderico Vital ou Roberto de Torigny (Morillo 1996: 17-19).

2 Para um estudo detalhado da Tapeçaria de Bayeux, profusamente documentado com miniaturas comentadas de todas as cenas deste bordado histórico, veja-se Rud 2001. 
Mas a fonte escrita de orientação normanda mais importante e mais útil na reconstituição da decisiva batalha de Hastings é, sem dúvida, a crónica de Guilherme de Poitiers, intitulada Gesta Guillelmi ducis Normannorum et regis Anglorum ("Gesta de Guilherme, duque dos Normandos e rei dos Ingleses"). Esta obra foi composta entre 1071 e 1077, num período em que a memória do combate estava ainda muito fresca e em que permaneciam vivas muitas testemunhas oculares do prélio. O relato de Guilherme de Poitiers foi impresso nos inícios do século XVII (1619) pelo famoso editor André Duchesne, que utilizou um manuscrito algo danificado e incompleto, nomeadamente nas suas partes inicial e final. Posteriormente, deu-se a infelicidade de este manuscrito único se perder, provavelmente por ocasião do incêndio que atingiu, em 1731, a chamada Cottonian Library - a biblioteca privada do maior antiquário e bibliófilo do período Stuart, Sir Rober Cotton, falecido em 1631 e cuja coleção parece ter estado na origem da fabulosa British Library.

A narrativa de Guilherme de Poitiers principia em 1047, ou seja, quase no início do reinado de Eduardo "O Confessor" (o monarca anglo-saxónico que, ao regressar de um longo exílio na Normandia, pôs fim ao curto domínio viquingue sobre a Inglaterra) e prolonga-se até 1068, dois anos volvidos sobre o terrível combate de Hastings e sobre a morte de Haroldo II Godwinson, o monarca que, em janeiro de 1066, substituíra no trono de Inglaterra o falecido Eduardo. Portanto, Guilherme teve oportunidade de expor as motivações remotas e próximas do conflito, enfatizando a circunstância de a entronização de Haroldo II em Westminster ter constituído uma flagrante violação das promessas repetidamente feitas, tanto por Eduardo como pelo próprio Haroldo, ao duque da Normandia, que assim acalentaria legítimas expetativas de se tornar rei de Inglaterra logo que Eduardo (seu parente remoto) falecesse ${ }^{3}$.

Guilherme de Poitiers deve ter nascido na Normandia (talvez em Les Préaux, nas proximidades de Pont-Audemer) na segunda metade da década de 1020. Oriundo de um clã nobre e abastado (tanto quanto se julga, aparentado ou vassalo da famosa linhagem dos Beaumont), Guilherme teve direito a uma educação requintada: estudou em Poitiers e recebeu instrução militar especializada, o que desde logo o capacitou para uma descrição particularmente precisa dos episódios militares que haveria de evocar nas suas narrativas. É provável que, durante a sua juventude, tenha chegado a servir na hoste do duque da Normandia, Guilherme II, que assumira desassombradamente o título ducal cerca de 1046 e que enfrentou, até ao início da década de 1050,

\footnotetext{
Sobre os antecedentes políticos da batalha de Hastings, veja-se, por todos Bradbury 2005.
} 
uma situação militar extremamente ingrata, que conseguiu superar ao vencer o conde de Anjou e o próprio rei de França (Henrique I), iniciando depois um processo de expansão do território normando que o levaria a conquistas importantíssimas nas regiões vizinhas da Bretanha e do Maine.

Estima-se que, em data muito próxima de 1050 (talvez um ano antes), Guilherme tenha decidido poisar as armas para abraçar a carreira eclesiástica. Terá estudado na famosa escola de Santo Hilário "O Grande", em Poitiers, e, de acordo com Orderico Vital (um escritor de origem normando-inglesa falecido em 1141 ou 1142, graças ao qual sabemos muito acerca de Guilherme de Poitiers, cuja crónica continuou e, em certo sentido, preservou até 1075), terá regressado à Normandia para aprofundar os seus conhecimentos literários, tornando-se com isso um dos homens mais cultos do seu tempo, pelo menos na região noroeste da atual França.

Graças a esta boa formação, simultaneamente marcial, eclesiástica, literária e jurídica, Guilherme mereceu a atenção e as boas graças do duque Guilherme II, de quem se tornou capelão, vindo mais tarde a obter a dignidade de Arquidiácono de Lisieux (é, aliás, nesta última qualidade que ele se apresenta como autor da Gesta). Tanto quanto sabemos, Guilherme de Poitiers não participou pessoalmente na batalha de Hastings, mas pouco depois da grande vitória normanda viajou para Inglaterra, onde serviu diligentemente o novo monarca como seu capelão. Nestas condições, teve acesso privilegiado a numerosas fontes orais (e, eventualmente, escritas também) sobre o grande combate, parecendo-nos também provável que tenha podido acompanhar, ainda que pontualmente, a feitura da Tapeçaria de Bayeux, de que era mandante um familiar próximo do seu senhor e que estaria em curso de produção numa cidade de enorme relevância eclesiástica (Canterbury) não demasiado distante da corte londrina!

O final de vida de Guilherme de Poitiers é mais incerto. Poderá, na sua velhice, ter-se simplesmente retirado para um estabelecimento eclesiástico da sua preferência (talvez Saint-Évroul, na diocese de Lisieux, onde pode muito bem ter conhecido Orderico Vital), mas poderá também ter sentido dificuldades em sobreviver politicamente ao conturbado período que correspondeu aos últimos anos do reinado de Guilherme (falecido em 1087) e aos primeiros anos do governo do seu sucessor, Guilherme "O Ruivo", anos esses durante os quais se fez sentir a forte contestação ao vencedor de Hastings por parte do seu primogénito (Roberto Courteheuse), para além de graves desentendimentos entre o rei Guilherme e o seu meio-irmão e bispo de Bayeux, Odão, que forçariam mesmo a fuga deste último para Itália. Esta leitura mais atribulada do final de vida do nosso autor parece corroborada por 
Orderico Vital, que alude às "circunstâncias desfavoráveis" que obrigaram o capelão a pôr de lado o trabalho acerca dos feitos do monarca seu patrono ${ }^{4}$.

De um modo geral, a descrição que Guilherme de Poitiers faz acerca do combate de Hastings é bastante equilibrada e fiável, ainda que não possamos esquecer a circunstância de o objetivo principal da narrativa consistir em elogiar o novo rei de Inglaterra e em justificar o mérito e até a justeza ética e moral da sua ascensão a esse título. Bom conhecedor da prosa latina, o capelão não hesita em recorrer a uma retórica heroica e a modelos clássicos (como, por exemplo, os "Comentários sobre a guerra da Gália", de Júlio César) para ornamentar a sua narrativa e imprimir-lhe a aura desejada, compatível com os pergaminhos conquistados pelo seu velho amigo e protetor, o duque normando, por via da estrondosa vitória alcançada no campo de batalha de Hastings.

Claro que esta dimensão panegírica do relato de Guilherme de Poitiers prejudica a sua qualidade como historiador e distorce parcialmente os retratos que ele apresenta das principais personagens envolvidas nesta história. Ainda assim, do ponto de vista militar (que é a perspetiva que aqui mais nos interessa), tanto pela sua contemporaneidade (realçada no próprio título da obra), como pela sua familiaridade com muitos dos protagonistas da batalha e ainda pelo seu bom conhecimento do território onde ocorreu a campanha (incluindo, provavelmente, o próprio campo de batalha, onde o duque-rei mandaria construir a formosa abadia de Battle), a abrangente e detalhada narrativa do capelão é absolutamente preciosa e insubstituível, superando qualquer outro relato do acontecimento.

Por esse motivo, entendemos que tinha chegado a hora de a dar a conhecer ao público de língua portuguesa, utilizando para tanto a lição latina mais adequada. Uma vez que estamos a centrar o objeto teórico do nosso trabalho no combate travado a 14 de outubro de 1066 , cerca de $11 \mathrm{~km}$ a norte de Hastings, limitaremos a nossa tradução a nove parágrafos da Segunda Parte da longa e minuciosa crónica de Guilherme de Poitiers, deixando para outra ocasião a possibilidade de traduzir integralmente, do latim para português, esta valiosa obra 5 .

Os parágrafos selecionados (Parte II, 17 a 25) incluem toda a descrição da batalha propriamente dita. À guisa de introdução, e para facilitar a consulta da fonte pelo leitor, podemos seccionar esta parte da narrativa em 10 fases principais:

4 Cf. The Gesta Gvillelmi of William of Poitiers 2006: XVI.

5 Para uma visão de conjunto da história política de Inglaterra ao tempo da campanha de Hastings, com todos os detalhes relevantes sobre a disputa que conduziu os exércitos normando e anglo-saxónico a dirimir forças no campo onde hoje está a abadia de Battle, veja-se Monteiro 2012: 189-327. 
1. O cronista começa por explicar que, depois de os dois exércitos inimigos se disporem no campo de batalha, foi a "fogosa audácia dos Normandos" que conduziu à abertura das hostilidades; o ataque inicial - à base de arqueiros, besteiros e tropas apeadas - foi intenso, mas os Ingleses aguentaram estoicamente a investida, com a infantaria anglo-saxónica a fazer jus ao seu prestígio e a arremessar lanças, dardos, machados e pedras contra os invasores. Com isto, os peões normandos foram obrigados a recuar, sob pena de serem "imediatamente esmagados por tudo isto, tal como por uma mole mortífera” (\$ 17).

2. O duque mandou então a sua cavalaria, que tinha formado em posição recuada, avançar e dar continuidade ao combate. Desse modo, os cavaleiros ao serviço de Guilherme (Normandos, mas também Bretões, Flamengos e outros) "tornam-se os primeiros" e, não desejando ser considerados cobardes, abdicam do combate à distância por meio do arremesso de lanças e "ousam travar combate com as espadas". Isto fez ressoar no campo de batalha um enorme clamor, "aqui normando, ali estrangeiro (...) abafado pelo ruído das armas e pelos gemidos dos moribundos". Nesta fase, os homens de Haroldo II achavam-se ainda em vantagem, pois ocupavam uma posição elevada na colina de Senlac (a referência toponímica deve-se a Orderico Vital), o que dava ainda maior força à sua "formação muito cerrada" e permitia tirar bom partido do seu "grande número e corpos robustíssimos", já para não falar na qualidade das suas armas, que facilmente penetravam os escudos e as restantes proteções defensivas dos normandos ( $\$ 17)$.

3. Graças a isto, os cavaleiros bretões e outra tropa montada auxiliar posicionada no lado esquerdo, "aterrorizados por esta violência", puseram-se em fuga. A debandada foi ainda estimulada por um rumor que circulou então no campo de batalha e que indicava que Guilherme tinha sido abatido! Com isso, "quase toda a linha do duque cede", sendo perseguida por uma grande quantidade de peonagem anglo-saxónica. Este boato terá estado relacionado com o facto de três dos cavalos de Guilherme terem sido liquidados durante a refrega, obrigando o chefe normando a encontrar montadas alternativas. Certo é que a situação se tornou gravíssima para os invasores, e só o sangue frio do duque permitiu evitar males maiores: Guilherme "correu ao encontro dos [normandos] que fugiam e barrou-lhes o passo"; a seguir, "descoberta a cabeça após ter levantado o elmo, disse em voz bem alta: 'Olhai para mim. Estou vivo e vencerei, com a ajuda de Deus. Que loucura vos leva a fugir? (...) Fugindo, nenhum de vós escapará à morte". Esta iniciativa do carismático líder, também documentada pelas belas ilustrações da Tapeçaria de Bayeux, permitiu estancar in extremis a fuga dos Normandos, que recobraram ânimo para reiniciar o assalto à parede de escudos adversária; pelo caminho, conseguiram ainda liquidar todos os seus perseguidores (o capelão fala, com evidente exagero, em 
"alguns milhares"), que já estariam a antegozar a vitória e que não contariam com esta reviravolta no ordenamento dos seus inimigos ( $\$ 17$ e 18).

4. O combate prossegue, mais aceso do que nunca, pois a hoste anglo-saxónica, embora tivesse sofrido "enormes baixas", continua a oferecer uma resistência tenaz, com os peões anglo-saxónicos a esforçarem-se por "não abrirem nenhuma brecha aos [cavaleiros normandos] que desejavam penetrar". Assim, a parede de escudos sob o comando de Haroldo II Godwinson mantinha-se de tal maneira cerrada que "os seus mortos mal podiam cair", por não terem espaço para o efeito $(\$ 19) \ldots$

5. É então que Guilherme, que não podia correr o risco de travar uma batalha com resultado indeciso, uma vez que era ele que atuava fora do seu território (para mais numa altura já bastante tardia do ano) e o seu adversário já tinha sido coroado em Westminster, decide recorrer a um estratagema há muito conhecido dos Normandos: a fuga simulada. O cronista explica que a ideia pode ter surgido quando os comandantes normandos se lembraram "da oportunidade favorável que, pouco antes, a fuga lhes tinha proporcionado" (vide supra, fase 3). Assim, "ao reconhecerem que não podiam vencer um inimigo tão numeroso e, ao mesmo tempo, tão resistente, os Normandos e os seus aliados voltaram as costas, simulando deliberadamente uma fuga”. Incautos, os homens de Haroldo II caíram na armadilha e rejubilaram prematuramente: "tal como antes tinha sucedido, alguns milhares, como se voassem, ousaram perseguir aqueles que julgavam que estavam a fugir". Ora, isto era justamente o que os Normandos pretendiam: subitamente, "fazendo meia-volta com os seus cavalos, mataram por toda a parte os inimigos surpreendidos e cercados, não deixando nenhum vivo” (\$20)!

6. Depois de recorrerem duas vezes a este estratagema da fuga simulada, os homens de Guilherme atacaram com "um entusiasmo ainda maior" os Ingleses, que resistiam como podiam na sua sólida posição, situada a meia altura da colina de Senlac. No entanto, apesar do ímpeto furioso dos invasores, galvanizados pelo sucesso da sua estratégia, continuava a revelar-se impossível penetrar a debilitada mas heroica muralha anglo-saxónica. O combate evolui então para uma fase algo incaracterística, "em que uma das partes avança com ataques e movimentos diferenciados e a outra resiste como que pregada ao chão" ( $\$ 21)$. Percebe-se que, nesta altura, fragilizados também pela morte prematura de dois dos irmãos de Haroldo II (Gyrd e Leofwine), os Ingleses só conseguem defender, não alimentando já nenhuma veleidade de voltar a ensaiar uma qualquer contra-ofensiva. Para Guilherme II, era uma questão de tempo, mas a tarde corria veloz e era bom que o líder normando assegurasse a vitória antes de a noite cair sobre o campo de batalha! 
7. Por volta das $19 \mathrm{~h}$, segundo as estimativas modernas, com um exército anglo-saxónico exausto (tanto mais que muitos dos efetivos tinham combatido a 25 de setembro em Stamford Bridge, perto de York, tendo sido obrigados a percorrer cerca de $700 \mathrm{~km}$ em regime de marcha forçada, em menos de um mês, para acorrerem aos fogos quase simultâneos das invasões norueguesa e normanda ${ }^{6}$ ), o duque, que de acordo com o seu capelão continuava a assumir um protagonismo decisivo na refrega, optou por jogar o seu derradeiro trunfo, claramente documentado na Tapeçaria de Bayeux: reuniu de novo os seus arqueiros e ordenou-lhes que avançassem outra vez para a linha da frente, tal como havia sucedido na fase inicial do prélio e como forma de debilitar definitivamente a parede de escudos inimiga, antes da investida final da cavalaria normanda: "Os Anglos enfraquecem e, como que confessando a sua culpa pela derrota, sofrem o castigo. Os Normandos lançam setas, ferem, trespassam; os mortos, ao cair, parecem mover-se mais do que os vivos. Não é permitido aos feridos ligeiros escapar, uma vez que a concentração dos seus companheiros os mata por esmagamento. E, assim, a fortuna correu a favor de Guilherme apressando o seu triunfo" (\$21).

8. A determinada altura, neste 'tudo por tudo' lançado já "ao fim do dia", o próprio rei de Inglaterra é abatido (segundo a Tapeçaria, por um disparo de flecha que lhe entrou pelo olho). O desfecho da batalha tornava-se, assim, irreversível: o exército anglo-saxónico, muito "enfraquecido devido à morte de muitas tropas", compreendeu que "já não era capaz de resistir aos Normandos por muito mais tempo", já que aqueles que ainda teimavam em lutar "estavam com as forças quase esgotadas" e não havia "auxílio algum que pudessem esperar". Desse modo, voltaram as costas e "puseram-se em fuga o mais rapidamente possível, uns em cavalos a que deitaram a mão, outros a pé; uma parte pelas estradas, outra, por lugares ermos. (...) Muitos acabaram cadáveres em florestas recônditas e muitos, caídos ao longo dos caminhos, foram um obstáculo para os que vinham atrás". Os Normandos, pelo seu lado, numa descarga de ódios e de medos bem típica de um final de batalha, perseguiam-nos com ardor, "golpeando-lhes as costas culpadas e consumando a vitória" (\$23).

9. Durante a fuga, alguns Ingleses conseguiram ainda refugiar-se numa "trincheira quebrada" com "numerosos fossos", isto é, numa zona de valas e de pregas traiçoeiras no terreno, onde atraíram e liquidaram muitos cavaleiros normandos que os perseguiam de forma menos organizada e mais eufórica. Guilherme, apesar dos avisos em sentido contrário do muito duvi-

6 Sobre a invasão do rei escandinavo Harald Hardrada e a batalha de Stamford Bridge, veja-se, por todos: DeVries 1999: passim. 
doso Eustáquio de Boulogne (cunhado de Eduardo "O Confessor") teve de acorrer para evitar males maiores, e lamentou a morte de alguns Normandos ilustres nesta fase tardia do combate, tanto mais que a sua coragem "foi inútil devido à desvantagem do terreno" ( $\$ 24)$. Anos mais tarde, a crónica escrita na abadia de Battle batizaria esta zona do campo de batalha com a designação de "Malfosse", e também Orderico Vital, a partir dos relatos de Guilherme de Poitiers e de Guilherme de Jumièges, aludiria a este incidente infeliz, que castigou duramente e de forma inesperada a hoste vitoriosa ${ }^{7}$.

10. Consumadas a fuga e a chacina, Guilherme e os seus homens regressaram ao campo de batalha, onde "a flor da nobreza e da juventude dos Anglos, manchada de sangue, cobria uma grande extensão do terreno”. Os corpos dos três irmãos Godwinson (Haroldo, Gyrd e Leofwine) foram encontrados perto uns dos outros, mas, segundo o capelão, o do monarca apenas "foi reconhecido por alguns sinais e não pela sua fisionomia", de tão desfigurado que estava. Seria levado para o acampamento do duque, onde a mãe o reclamou, oferecendo "pelo corpo do filho querido o seu peso em ouro". Em vão: Guilherme tinha consciência de que "não era digno receber ouro por uma tal transação", além de que - supomos nós - também não estaria interessado em fomentar qualquer culto de um mártir. Por isso, explica o capelão com ironia mordaz, mandou-o sepultar em local desconhecido, junto à costa, "como guardião do litoral e do mar que ele [Haroldo, prevendo a invasão normanda], como um louco, antes tinha ocupado pelas armas" (\$ 25) ...

Terminava assim, de forma dramática, faz agora precisamente 950 anos, um dos dias mais longos e mais decisivos da história medieval europeia. Restava a Guilherme de Poiters, o clérigo que fora soldado e que nos deixou a melhor narrativa da batalha, sentenciar moralmente o desfecho do ordálio. Afinal, a vitória do duque da Normandia não fora senão a comprovação da estultícia e do perjúrio do jovem monarca anglo-saxónico. Nos céus da velha Bretanha, o aparecimento de um "cometa" (sabemos hoje que se tratou do cometa Halley, que fez a sua aparição a 24 de abril de 1066 e que foi visível durante cerca de uma semana) bem que tinha predito a desgraça do rei usurpador ${ }^{8} .$.

\footnotetext{
Cf. Brown 1996: 215-216. De acordo com Bradbury 2005: 154, o "Malfosse" (entretanto identificado pelos investigadores que mais demoradamente examinaram o campo de batalha) situa-se cerca de 580 metros a norte da colina de Caldbec (um pouco acima de Senlac) e configura um obstáculo formado por uma ravina íngreme, delimitada por arbustos e incluindo também uma linha de água.

8 Este juízo moral e a referência ao cometa ocupam as últimas linhas do $\$ 25$ da Segunda Parte da Gesta, as quais não foram incluídas na nossa tradução por razões de economia de espaço e por já não dizerem respeito à descrição da batalha.
} 


\section{APÊNDICE \\ GESTA GVILLELMI DVCIS NORMANNORVM ET REGIS ANGLORVM A \\ GVILLELMO PICTAVENSI LEXIOVIORVM ARCHIDIACONO \\ CONTEMPORANEO SCRIPTA ${ }^{9}$ \\ PARS SECVNDA}

\section{(...)}

17. Terribilis clangor lituorum pugnae signa cecinit utrinque. Normannorum alacris audacia pugnae principium dedit. Taliter cum oratores in iudicium litem agunt de rapina, prior ferit dictione qui crimen intendit. Pedites itaque Normanni propius accedentes prouocant Anglos, missilibus in eos uulnera dirigunt atque necem. Illi contra fortiter, quo quisque ualet ingenio, resistunt. Iactant cuspides ac diuersorum generum tela, saeuissimas quasque secures, et lignis imposita saxa. Iis, ueluti mole letifera, statim nostros obrui putares. Subueniunt equites, et qui posteriores fuere fiunt primi. Pudet eminus pugnare, gladiis rem gerere audent. Altissimus clamor, hinc Normannicus, illinc barbaricus, armorum sonitu et gemitu morientium superator. Sic aliquandiu summa ui certatur ab utrisque. Angli nimium adiuuantur superioris loci opportunitate, quem sine procursu tenent, et maxime conferti; ingenti quoque numerositate sua atque ualidissima corpulentia; praeterea pugnae instrumentis, quae facile per scuta uel alia tegmina uiam inueniunt. Fortissime itaque sustinent uel propellunt ausos in se districtum ensibus impetum facere. Vulnerant et eos qui eminus in se iacula coniiciunt. Ecce igitur hac saeuitia perterriti auertuntur pedites pariter atque equites Britanni, et quotquot auxiliares erant in sinistro cornu; cedit fere cuncta ducis acies, quod cum pace dictum sit Normannorum inuictissimae nationis. Romanae maiestatis exercitus, copias regum continens, uincere solitus terra marique, fugit aliquando, cum ducem suum sciret aut crederet occisum. Credidere Normanni ducem ac dominum suum cecidisse. Non ergo nimis pudenda fuga cessere; minime uero dolenda, cum plurimum iuuerit.

18. Princeps namque prospiciens multam partem aduersae stationis prosiluisse, et insequi terga suorum, fugientibus occurrit et obstitit, uerberans aut minans hasta. Nudato insuper capite detractaque galea exclamans. 'Me', inquit, 'circumspicite. Viuo

9 Versão latina publicada por R. H. C. Davis e Marjorie Chibnall (2006). The GESTA GVILLELMI of William of Poitiers. Oxford: Clarendon Press, 2006 (ed. orig: 1998); o trecho selecionado (Parte II, parágrafos 17 a 25), alusivo à batalha de Hastings, encontra-se nas pp. 128-141. Os editores-tradutores utilizaram como fonte principal o texto de André Duchesne (Paris, 1619), o primeiro editor desta obra, que se baseou num manuscrito da famosa livraria de Sir Robert Cotton. Considera-se que a edição de Duchesne deve ser muito próxima da original, mas Davis e Chibnall compararam-na ainda com a edição mais recente de Raymonde Foreville (Paris, 1952), a quem se deve a divisão da obra em duas Partes e 108 capítulos, assim como com a História Eclesiástica de Orderico Vital, entre outros manuscritos. 
et uincam, opitulante Deo. Quae uobis dementia fugam suadet? Quae uia patebit ad effugiendum? Quos ut pecora mactare potestis, depellunt uos et occidunt. Victoriam deseritis, ac perpetuum honorem; in exitium curritis ac perpetuum opprobrium. Abeundo mortem nullus uestrum euadet.' His dictis receperunt animos. Primus ipse procurrit fulminans ense, strauit aduersam gentem, quae sibi, regi suo, rebellans commeruit mortem. Exardentes Normanni et circumuenientes aliquot millia insecuta se, momento deleuerunt ea, ut ne quidem unus superesset.

19. Ita confirmati, uehementius immanitatem exercitus inuaserunt, qui maximum detrimentum passus non uidebatur minor. Angli confidenter totis uiribus oppugnabant, id maxime laborantes, ne quem aditum irrumpere uolentibus aperirent. $\mathrm{Ob}$ nimiam densitatem eorum labi uix potuerunt interempti. Patuerunt tamen in eos uiae incisae per diuersas partes fortissimorum militum ferro. Institerunt eis Cenomanici, Francigenae, Britanni, Aquitani, sed cum praecipua uirtute Normanni. Tiro quidam Normannus Rodbertus, Rogerii de Bellomonte filius, Hugonis de Mellento comitis ex Adelina sorore nepos et haeres, praelium illo die primum experiens, egit quod aeternandum esset laude: cum legione, quam in dextro cornu duxit, irruens ac sternens magna cum audacia. Non est nostrae facultatis, nec permittit intentio nostra, singulorum fortia facta pro merito narrare. Copia dicendi ualentissimus, qui bellum illud suis oculis didicerit, difficillime singula quaeque persequeretur. At huc nos illo properamus, ut finita Guillelmi comitis laude, Guillelmi regis gloriam scribamus.

20. Animaduertentes Normanni sociaque turba, non absque nimio sui incommodo hostem tantum simul resistentem superari posse, terga dederunt, fugam ex industria simulantes. Meminerunt quam optatae rei paulo ante fuga dederit occasionem. Barbaris cum spe uictoriae ingens laetitia exorta est. Sese cohortantes exultante clamore nostros maledictis increpabant, et minabantur cunctos illico ruituros esse. Ausa sunt ut superius aliquot milia quasi uolante cursu, quos fugere putabant, urgere. Normanni repente regiratis equis interceptos et inclusos undique mactauerunt, nullum relinquentes.

21. Bis eo dolo simili euentu usi, reliquos maiori cum alacritate aggressi sunt: aciem adhuc horrendam, et quam difficillimum erat circumuenire. Fit deinde insoliti generis pugna, quam altera pars incursibus et diuersis motibus agit, altera uelut humo affixa tolerat. Languent Angli, et quasi reatum ipso defectu confitentes, uindictam patiuntur. Sagittant, feriunt, perfodiunt Normanni: mortui plus dum cadunt, quam uiui, moueri uidentur. Leuiter sauciatos non permittit euadere, sed comprimendo necat sociorum densitas. Ita felicitas pro Guillelmo triumpho maturando cucurrit.

22. Interfuerunt huic praelio Eustachius Boloniae comes, Guillelmus Ricardi Ebroicensis comitis filius, Goisfredus Rotronis Moritoniae comitis filius, Guillelmus Osberni filius, Haimerius Toarcensis praeses, Gualterius Giffardus, Hugo de 
Monteforti, Rodolphus de Toneia, Hugo de Grentmaisnil, Guillelmus de Guarenna, aliique quamplures militaris praestantiae fama celebratissimi et quorum nomina historiarum uoluminibus inter bellicosissimos commendari deceat. Guillelmus uero, dux eorum, adeo praestabat eis fortitudine, quemadmodum prudentia, ut antiquis ducibus Graecorum siue Romanorum qui maxime scriptis laudantur, aliis merito sit praeferendus, aliis comparandus. Nobiliter duxit ille cohibens fugam, dans animos, periculi socius; saepius clamans ut uenirent, quam iubens ire. Vnde liquido intelligitur uirtutem illi praeuiam pariter fecisse militibus iter et audaciam. Cor amisit absque uulnere pars hostium non modica, prospiciens hunc admirandum ac terribilem equitem. Equi tres ceciderunt sub eo confossi. Ter ille desiluit intrepidus, nec diu mors uectoris inulta remansit. Hic uelocitas eius, hic robur eius uideri potuit corporis et animi. Scuta, galeas, loricas, irato mucrone et moram dedignante penetrauit; clipeo suo nonnullos collisit. Mirantes eum peditem sui milites, plerique confecti uulneribus, corde sunt redintegrati. Et nonnulli, 'quos iam sanguis ac uires deficiunt', scutis innixi uiriliter depugnant, aliqui uoce et nutibus, cum aliud non ualent, socios instigant, ne timide ducem sequantur, ne uictoriam e manibus dimittant. Auxilio ipse multis atque saluti fuit.

Cum Heraldo, tali qualem poemata dicunt Hectorem uel Turnum, non minus auderet Guillelmus congredi singulari certamine, quam Achilles cum Hectore, uel Aeneas cum Turno. Tydeus aduersum insidiatos quinquaginta rupis petiuit opem: Guillelmus par, haud inferior loco, solus non extimuit mille. Scriptor Thebaidos uel Aeneidos, qui libris in ipsis poetica lege de magnis maiora canunt, ex actibus huius uiri aeque magnum, plus dignum conficerent opus uera canendo. Profecto, si quantum dignitas materiae suppeditaret carminibus ediscererent condecentibus, inter diuos ipsorum stili uenustate transferrent eum. Nostra uero tenuis prosa, titulatura ipsius humillime regnantibus pietatem in cultu ueri Dei, qui solus ab aeterno in finem seculorum et ultra Deus est, praelium quo tam fortiter quam iuste uicit, ueraci termino breuique concludat.

23. Iam inclinato die haud dubie intellexit exercitus Anglorum se stare contra Normannos diutius non ualere. Nouerunt se diminutos interitu multarum legionum; regem ipsum et fratres eius, regnique primates nonnullus occubuisse; quotquot reliqui sunt prope uiribus exhaustos; subsidium quod expectent nullum relictum. Viderunt Normannos non multum decreuisse peremptorum casu, et quasi uirium incrementa pugnando sumerent, acrius quam in principio imminere; ducis eam saeuitiam quae nulli contra stanti parceret; eam fortitudinem quae nisi uictrix non quiesceret. In fugam itaque conuersi quantotius abierunt, alii raptis equis, nonnulli pedites; pars per uias, plerique per auia. Iacuerunt in sanguine qui niterentur, aut surgerent non ualentes profugere. Valentes fecit aliquos salutem ualde cupiens animus. Multi siluestribus in abditis remanserunt cadauera, plures obfuerunt sequentibus 
per itinera collapsi. Normanni, licet ignari regionis, auide insequebantur, caedentes rea terga, imponentes manum ultimam secundo negotio. A mortuis etiam equorum ungulae supplicia sumpsere, dum cursus fieret super iacentes.

24. Rediit tamen fugientibus confidentia, nactis ad renouandum certamen maximam opportunitatem praerupti ualli et frequentium fossarum. Gens equidem illa natura semper in ferrum prompta fuit, descendens ab antiqua Saxonum origine ferocissimorum hominum. Propulsi non fuissent, nisi fortissima ui urgente. Regem Noricorum, magno exercitu fretum et bellicoso, quam facile nuper uicerunt. Cernens autem felicium signorum ductor cohortes inopinato collectas, quamuis nouiter aduenire subsidium putaret, non flexit iter neque substitit, terribilior cum parte hastae quam grandia spicula uibrantes, Eustachium comitem cum militibus quinquaginta auersum, et receptui signa canere uolentem, ne abiret uirili uoce compellauit. Ille contra familiariter in aurem ducis reditum suasit, proximam ei, si pergeret, mortem praedicens. Haec inter uerba percussus Eustachius inter scapulas ictu sonoro, cuius grauitatem statim sanguis demonstrabat naribus et ore, quasi moribundus euasit ope comitum. Dux formidinem omnino dedignans aut dedecus, inuadens protriuit aduersarios. In eo congressu Normannorum aliqui nobiliores ceciderunt, aduersitate loci uirtute eorum impedita.

25. Sic uictoria consummata, ad aream belli regressus, reperit stragem, quam non absque miseratione conspexit, tametsi factam in impios; tametsi tyrannum occidere sit pulchrum, fama gloriosum, beneficio gratum. Late solum operuit sordidatus in cruore flos Anglicae nobilitatis atque iuuentutis. Propius regem fratres eius duo reperti sunt. Ipse carens omni decore, quibusdam signis, nequaquam facie, recognitus est, et in castra ducis delatus qui tumulandum eum Guillelmo agnomine Maletto concessit, non matri pro corpore dilectae prolis auri par pondus offerenti. Sciuit enim non decere tali commercio aurum accipi. Aestimauit indignum fore ad matris libitum sepeliri, cuius ob nimiam cupiditatem insepulti remanerent innumerabiles. Dictum est illudendo, oportere situm esse custodem littoris et pelagi, quae cum armis ante uesanus insedit ${ }^{10}$.

10 Termina aqui o relato da batalha, embora, tal como explicámos no final da nossa Apresentação, Guilherme de Poitiers ainda acrescente uma dezena e meia de linhas ao $\$ 25$, com o propósito visível de justificar moralmente o desfecho do combate. 


\section{GESTA DE GUILHERME, DUQUE DOS NORMANDOS E REI DOS INGLESES, ESCRITA NO SEU TEMPO POR GUILHERME DE POITIERS, ARQUIDIÁCONO DE LISIEUX SEGUNDA PARTE ${ }^{11}$}

\section{(...)}

17. O estrépito medonho das trombetas fez soar de ambos os lados o sinal para o combate. A fogosa audácia dos Normandos deu início ao prélio, tal como quando num processo judicial os oradores litigam sobre um crime de roubo e é aquele que promove a acusação o primeiro a apresentar as alegações. E assim, os peões normandos, ao aproximarem-se, atacaram os Anglos e infligiram-lhes ferimentos e a morte por meio de mísseis. Os Anglos, por sua vez, resistem corajosamente, cada qual fazendo valer as suas capacidades. Arremessam dardos e projéteis de diferentes tipos, machados pesadíssimos e pedras agarradas a cabos de madeira. Julgar-se-ia que os nossos seriam imediatamente esmagados por tudo isto, tal como por uma mole mortífera. Os cavaleiros vêm então em [seu] socorro e aqueles que [antes] estavam na retaguarda tornam-se os primeiros. Tendo vergonha de lutar à distância, ousam travar combate com as espadas. $\mathrm{O}$ altíssimo clamor, aqui normando, ali estrangeiro, é abafado pelo ruído das armas e pelos gemidos dos moribundos. E assim se luta durante algum tempo de ambos os lados com suma violência. Os Anglos são bastante ajudados pela vantagem de uma posição mais elevada, que ocupam sem se deslocarem e em formação muito cerrada, bem como pelo seu grande número e corpos robustíssimos; para além disso, têm a vantagem das armas de combate, que facilmente encontram uma passagem através de escudos e de outras proteções. E assim travam com grande vigor e até repelem aqueles que ousam lançar-lhes um ataque de espadas na mão. E até ferem aqueles que à distância arremessam dardos contra eles. E eis que então, aterrorizados por esta violência, os peões, bem como os cavaleiros bretões e quantos auxiliares estavam no flanco esquerdo, se põem em fuga; quase toda a linha do duque cede, algo que [só] se poderá dizer com a permissão da mui invicta nação dos Normandos. O exército do império romano, que englobava tropas de elite e que estava habituado a vencer em terra e no mar, por vezes fugiu, ao saber ou convencer-se de que o seu chefe tinha sido morto. Os Normandos acreditaram que o seu duque e senhor tinha tombado. Portanto, recuaram numa fuga não muito vergonhosa e, na verdade, de modo nenhum prejudicial, uma vez que muito os ajudaria depois.

18. Com efeito, o seu chefe, ao ver que uma grande parte da formação adversária se tinha precipitado para a frente e perseguia os seus, correu ao encontro

11 Tradução de João Gouveia Monteiro. Devemos um agradecimento sentido ao nosso querido e saudoso amigo e Mestre, Dr. José Eduardo Braga, que, pouco antes de falecer (em 2012), iniciou este projeto connosco e reviu ainda os primeiros trechos desta tradução. 
dos que fugiam e barrou-lhes o passo, batendo-lhes e ameaçando-os com a lança. E além disso, descoberta a cabeça após ter levantado o elmo, disse em voz bem alta: 'Olhai para mim. Estou vivo e vencerei, com a ajuda de Deus. Que loucura vos leva a fugir? Que caminho se abrirá para a fuga? Podeis abater como gado aqueles que vos repelem e matam. Desperdiçais a vitória e a glória eterna; correis para a ruína e para o opróbrio eterno. Fugindo, nenhum de vós escapará à morte. Dito isto, eles recobraram o ânimo. E ele mesmo avançou em primeiro lugar, fulminando com a sua espada e abateu a gente inimiga que, ao revoltar-se contra ele, o seu rei, mereceu a morte. Os Normandos, repletos de ardor e cercando alguns milhares que os tinham perseguido, liquidaram-nos num ápice, de tal forma que nenhum sobreviveu.

19. Encorajados por este sucesso, atacaram com mais energia o grosso do exército inimigo, que não parecia diminuído apesar de ter sofrido enormes baixas. Os Anglos lutavam cheios de confiança com todas as suas capacidades, esforçando-se sobretudo em não abrirem nenhuma brecha aos que desejavam penetrar. Devido à sua formação bastante cerrada, os seus mortos mal podiam cair. Contudo, surgiram entre eles aberturas em diferentes partes talhadas pelo ferro de guerreiros valentíssimos. Faziam-lhes frente homens do Maine, da Ilha-de-França, da Bretanha e da Aquitânia, mas com especial coragem os da Normandia. Um certo mancebo normando, Roberto, filho de Rogério de Beaumont, sobrinho e herdeiro de Hugo (conde de Melun) por parte da irmã Adelina, que travava naquele dia a sua primeira batalha, praticou um feito que devia ser eternizado pela glória: com o esquadrão que ele chefiava no flanco direito, caiu sobre os inimigos e aniquilou-os com uma grande audácia. Não está nas nossas competências nem nos permite o nosso propósito narrar os altos feitos de cada um de acordo com o seu mérito. $\mathrm{O}$ escritor mais notável pelos seus dotes oratórios que tenha presenciado esta batalha com os seus próprios olhos muito dificilmente poderia ter seguido cada uma das ações. Mas, por agora, nós apressamo-nos para que, depois de terminar o louvor do conde Guilherme, celebremos o louvor do rei Guilherme.

20. Ao reconhecerem que não podiam vencer um inimigo tão numeroso e, ao mesmo tempo, tão resistente, os Normandos e os seus aliados voltaram as costas simulando deliberadamente uma fuga. Lembravam-se da oportunidade favorável que, pouco antes, a fuga lhes tinha proporcionado. Entre os bárbaros surgiu uma imensa alegria com a esperança da vitória. Exortando-se mutuamente com um clamor exuberante, incentivavam os nossos com injúrias e ameaçavam que todos cairiam de imediato. Tal como antes tinha sucedido, alguns milhares, como se voassem, ousaram perseguir aqueles que julgavam que estavam a fugir. De repente, os Normandos, fazendo meia-volta com os seus cavalos, mataram por toda a parte os inimigos surpreendidos e cercados, não deixando nenhum vivo.

21. Tendo usado duas vezes este estratagema com o mesmo sucesso, atacaram os restantes com um entusiasmo ainda maior. Até esse momento, era muitíssimo difícil cer- 
car a terrível formação inimiga. Trava-se então um combate de natureza insólita, em que uma das partes avança com ataques e movimentos diferenciados e a outra resiste como que pregada ao chão. Os Anglos enfraquecem e, como que confessando a sua culpa pela derrota, sofrem o castigo [respetivo]. Os Normandos lançam setas, ferem, trespassam; os mortos, ao cair, parecem mover-se mais do que os vivos. Não é permitido aos feridos ligeiros escapar, uma vez que a concentração dos seus companheiros os mata por esmagamento. E assim, a fortuna correu a favor de Guilherme apressando o seu triunfo.

22. Participaram nesta batalha: Eustáquio, conde de Boulogne; Guilherme, filho de Ricardo, conde de Évreux; Godofredo, filho de Rotrou, conde de Mortagne; Guilherme, filho de Osberno; Aimeri, visconde de Thouars; Gualter Giffard; Hugo de Montfort; Rodolfo de Tosny; Hugo de Grandmesnil; Guilherme de Warenne; e muitíssimos outros ilustríssimos pela sua reputação de excelência militar, cujos nomes será mister louvar como entre os mais aguerridos nos livros de História. Mas Guilherme, o seu duque, em tanto os superava em coragem bem como em sabedoria que perante os antigos generais de Gregos e Romanos, que muito são louvados em escritos, ele tem de ser colocado à frente de uns pelo seu valor, ou deve equiparar-se a outros. Ele comandou os seus com distinção, travando a sua fuga, transmitindo coragem, partilhando o perigo; muito mais vezes os chamava para que o seguissem do que ordenava que fossem à frente dele. De tudo isto, percebe-se com clareza que a sua coragem na frente de combate abriu caminho aos seus soldados e incutiu-lhes audácia. Uma parte não despicienda dos inimigos perdeu o ânimo sem ter sofrido qualquer ferimento ao avistar este cavaleiro digno de admiração e terrível. Três cavalos caíram debaixo dele, trespassados. Três vezes ele desmontou intrépido e não deixou por muito tempo sem vingança a morte da montada. Aqui, podia-se ver a sua agilidade, ali o vigor do seu corpo e do seu espírito. Trespassou escudos, capacetes e lorigas com a sua espada furiosa e que desdenhava qualquer pausa. Com o seu escudo, arredou alguns. Ao vê-lo combater a pé, os seus cavaleiros, muitos deles cobertos de feridas, recuperaram o ânimo. E alguns, 'a quem o sangue e as forças já faltam'12, combatem corajosamente apoiados nos escudos; alguns, como nada mais podem fazer, instigam os companheiros com a voz e com gestos a seguir sem medo o duque e a não deixar escapar das mãos a vitória. E o próprio duque foi um auxílio e salvação para muitos.

Guilherme tanto ousaria travar um combate singular com Harold, que os poemas dizem tal e qual Heitor ou Turno, quanto Aquiles com Heitor ou Eneias com Turno. Contra 50 inimigos emboscados, Tideu procurou o auxílio de uma rocha. Guilherme, seu igual e de nascimento não inferior, sozinho não teve medo de 1.000. Os autores da Tebaida e da Eneida, que nos seus livros cantam grandes feitos tornando-os maiores de acordo com a lei da poesia, comporiam sobre as ações deste homem uma obra

12 César, De bello gallico, VII, 50: quem iam sanguis viresque deficiunt. 
igualmente grande e mais digna de louvor, cantando a verdade. Com efeito, se eles desenvolvessem em poemas adequados tudo quanto a dignidade do assunto apresenta, eles colocá-lo-iam entre os deuses em conformidade com a beleza do seu estilo. Mas que a nossa modesta prosa, que há-de mostrar humildemente aos que reinam a piedade do duque na adoração do Deus verdadeiro, que é o único deus desde a eternidade até ao fim dos séculos e para além deles, conclua num final fidedigno e breve a narração desta batalha em que ele venceu tão corajosa quanto justamente.

23. Já ao fim do dia, o exército dos Anglos percebeu claramente que já não era capaz de resistir aos Normandos por muito mais tempo. Eles sabiam que estavam enfraquecidos devido à morte de muitas tropas, que o próprio rei e os irmãos e alguns grandes do reino tinham sucumbido; sabiam ainda que todos os restantes estavam com as forças quase esgotadas e que não havia auxílio algum que pudessem esperar. Eles viam que os Normandos não tinham enfraquecido muito pelas baixas sofridas, como se ao combaterem as suas forças aumentassem, e que pressionavam mais energicamente do que no início; viam também aquela fúria do duque, que não poupava ninguém que lhe fizesse frente; e aquela firmeza que não acalma a não ser com a vitória. E assim, voltando as costas, os Anglos puseram-se em fuga o mais rapidamente possível, uns em cavalos a que deitaram a mão, outros a pé; uma parte, pelas estradas, outra por lugares ermos. Alguns que se esforçavam por fugir jaziam em sangue, outros estavam em pé mas não tinham forças para isso. A enorme vontade de se salvarem tornou alguns em valentes. Muitos acabaram cadáveres em florestas recônditas e muitos, caídos ao longo dos caminhos, foram um obstáculo para os que vinham atrás. Os Normandos, ainda que desconhecedores da região, perseguiam-nos arduamente golpeando-lhes as costas culpadas e consumando a vitória. E até os cascos dos cavalos infligiam punições aos mortos enquanto galopavam por cima dos que estavam caídos.

24. Contudo, a confiança regressou aos fugitivos, que encontraram uma excelente oportunidade para regressar ao combate proporcionada por uma trincheira quebrada e por numerosos fossos. Na verdade, este povo sempre foi inclinado a pegar em armas descendendo da antiga raça dos Saxões, homens muito corajosos. Eles não teriam sido repelidos se não tivessem sido atacados por uma força poderosíssima. Recentemente, eles tinham vencido com enorme facilidade o rei dos Noruegueses, apoiado por um grande e aguerrido exército. Mas o comandante dos afortunados estandartes, ao ver as tropas adversárias inesperadamente aglomeradas, não alterou o seu trajeto nem se deteve ainda que pensasse que estavam a chegar reforços; mais terrível ao simplesmente empunhar a [sua] lança quebrada do que aqueles que brandiam longos dardos, obrigou com a sua potente voz o conde Eustáquio, que fugia com 50 cavaleiros e que queria soar a retirada, a não se afastar. Eustáquio, em resposta, aconselhou a retirada falando com intimidade ao ouvido do duque, predizendo que a morte deste seria iminente caso avançasse. Ao dizer estas palavras, 
Eustáquio foi atingido entre os ombros por um golpe que soou forte e cuja gravidade logo se revelou pelo sangue que jorrou das narinas e da boca; e salvou-se moribundo com o auxílio dos companheiros. $\mathrm{O}$ duque, desdenhando completamente o medo e a desonra, atacou os inimigos e desbaratou-os. Neste combate, tombaram alguns dos Normandos mais ilustres, cuja coragem foi inútil devido à desvantagem do terreno.

25. Consumada assim a vitória, o duque, regressando ao campo de batalha, deu-se conta da carnificina, que contemplou com comiseração ainda que esta tivesse sido infligida a ímpios e ainda que matar um tirano seja nobre, honroso, glorioso pela fama que concede e digno de reconhecimento pelo benefício que daí advém. A flor da nobreza e da juventude dos Anglos, manchada de sangue, cobria uma grande extensão do terreno. Os dois irmãos do rei foram encontrados muito perto dele. E o próprio Haroldo, despojado de todas as insígnias, foi reconhecido por alguns sinais e não pela sua fisionomia; foi levado para o acampamento do duque que o entregou a Guilherme, dito Malet, para o sepultar, e não à sua mãe, que oferecia pelo corpo do filho querido o seu peso em ouro. Guilherme sabia, com efeito, que não era digno receber ouro por uma tal transação. Ele pensava que seria indigno sepultar de acordo com a vontade da mãe aquele cuja ambição desmedida deixava sem sepultura um incontável número de homens. Disse-se, por zombaria, que Haroldo devia ser colocado como guardião do litoral e do mar que ele, como um louco, antes tinha ocupado pelas armas.

\section{Bibliografia}

\section{Fontes}

The Gesta Gvillelmi of William of Poitiers (2006). Edited and translated by R. C. H. Davis and Marjorie Chibnall. Oxford: Clarendon Press (ed. orig: 1998).

\section{Estudos}

BRADBURY, Jim (2005). The Battle of Hastings. Stroud: Sutton Publishing (ed. orig: 1998). BROWN, R. Allen (1996). “The Battle of Hastings”, in Stephen Morillo (ed.), The Battle of Hastings. Sources and Interpretations. Woodbridge: The Boydell Press.

DEVRIES, Kelly (1999). The Norwegian Invasion of England in 1066. Woodbridge: The Boydell Press.

MONTEIRO, João Gouveia (2012). Grandes conflitos da história da Europa. Coimbra: Imprensa da Universidade de Coimbra.

MORILLO, Stephen (1996). The Battle of Hastings. Sources and Interpretations. Woodbridge: The Boydell Press.

RUD, Mogens (2001). La Tapisserie de Bayeux et la bataille de Hastings 1066. trad. francesa, 4. ${ }^{a}$ ed. Copenhague: Christian Ejlers (ed. orig: 1983). 